\title{
Emergent Constraints in Climate Projections: A Case Study of Changes in High-Latitude Temperature Variability ${ }^{\mathscr{D}}$
}

\author{
AleKsandra Borodina, ERICH M. Fischer, AND Reto KNUTTI \\ Institute for Atmospheric and Climate Science, ETH Zurich, Zürich, Switzerland
}

(Manuscript received 8 September 2016, in final form 18 January 2017)

\begin{abstract}
Climate projections from phase 5 of the Coupled Model Intercomparison Project (CMIP5) ensemble show a decrease in interannual surface temperature variability over high latitudes with a large intermodel spread, in particular over the areas of sea ice retreat. Here relationships are found between the models' present-day performance in sea ice-related metrics and future changes in temperature variability. These relations, so-called emergent constraints, can produce ensembles of models calibrated with present-day observations with a narrower spread across their members than across the full ensemble. The underlying assumption is that models in better agreement with observations or reanalyses in a carefully selected metric probably have a more realistic representation of local processes, and therefore are more reliable for projections. Thus, the reliability of this method depends on the availability of high-quality observations or reanalyses. This work represents a step toward formalization of the emergent constraints framework, as so far there is no consensus on how the constraints should be best implemented. The authors quantify the reduction in spread from emerging constraints for various metrics and their combinations, different emission scenarios, and seasons. Some of the general features of emerging constraints are discussed, and how to effectively aggregate information across metrics and seasons to achieve the largest reduction in model spread. It is demonstrated, based on the case of temperature variability, that a robust constraint can be obtained by combining relevant metrics across all seasons. Such a constraint results in a strongly reduced spread across model projections, which is consistent with a process understanding of variability changes due to sea ice retreat.
\end{abstract}

\section{Introduction}

Different temperature responses of climate models to a certain forcing lead to a wide range of projections by the end of the century (Knutti and Sedláček 2012; Stocker et al. 2013). Similarly, projected changes in temperature variability show a substantial spread across models (e.g., Kjellström et al. 2007; Ylhäisi and Räisänen 2014; Fischer and Schär 2009). These changes in the warming climate have received a lot of attention from the scientific community, especially when they translate to severity and frequency of weather extremes (Fischer and Schär 2009; De Vries et al. 2012; Screen 2014; Francis and Vavrus 2015). However, the magnitude and the sign of the change of temperature variability vary locally and temporally due

Supplemental information related to this paper is available at the Journals Online website: http://dx.doi.org/10.1175/ JCLI-D-16-0662.s1.

Corresponding author e-mail: Aleksandra Borodina, aleksandra. borodina@env.ethz.ch to different processes that come in play. For instance, in summer months, an increase in temperature variability over central and southern Europe has been observed (Della-Marta et al. 2007) that is projected to continue and intensify into the future (e.g., Schär et al. 2004; Beniston and Stephenson 2004; Seneviratne et al. 2006; Fischer and Schär 2009; Fischer et al. 2012). In contrast, for landmasses at high latitudes, temperature variability in cold months is expected to decrease (Huntingford et al. 2013; Schneider et al. 2015; Screen 2014). Cold extremes in northern Europe are projected to warm faster than the mean (De Vries et al. 2012; Kharin et al. 2013), leading to reduced temperature variability. Such behavior over high latitudes was linked to changes in storm track activity (Colle et al. 2013), changes in snow cover (Dutra et al. 2011), changes in land-sea contrast (De Vries et al. 2012), advection of air masses (Screen 2014; Schneider et al. 2015), and sea ice retreat (Cohen et al. 2012; Screen and Simmonds 2013; Vihma 2014). Over the Arctic region, the interannual temperature variability has been shown to diminish as a direct effect of the sea ice retreat due to increased maritime influence (Bintanja and van der 
Linden 2013; Johannessen et al. 2004; Blackport and Kushner 2016). The ocean has much larger heat capacity than the atmosphere and therefore will make the temperature less variable over the ocean that over sea ice which acts as a barrier. In addition, sea ice retreat results in amplified local warming as well as an increase in turbulent heat fluxes into the atmosphere (e.g., Deser et al. 2010; Screen et al. 2014). Aside from the local effect on interannual temperature variability, model experiments suggest that disappearing sea ice can also have remote effect on the midlatitudinal weather (e.g., Screen et al. 2015; Sun et al. 2015; Blackport and Kushner 2016). For example, the atmospheric response to sea ice retreat in winter can manifest itself as the negative phase of the northern annular mode (NAM) (e.g., Peings and Magnusdottir 2014; Deser et al. 2010) and a slightly weakened stratospheric vortex (Sun et al. 2015). The effects of sea ice retreat are suggested to be even more farreaching due to ocean feedbacks (Deser et al. 2015). How important these effects are and how these are related to temperature variability is still under debate given the high complexity of the climate and large internal variability of high-latitudinal circulation (Kretschmer et al.2016; Cohen et al. 2014; Overland et al. 2016). Future changes in temperature variability are therefore an uncertain yet important quantity, and society would benefit if a simple method using observations could be used to narrow the spread across models and increase the confidence in the projected changes.

In this work we focus on changes in local temperature variability of the polar regions to illustrate the concept of emergent constraints. An emergent constraint is based on a relationship between the observed behavior and projections that arises empirically from the climate model output. The empirical relationship is used in conjunction with observations to limit the range of plausible projections by selecting a set of models that are consistent with observations. This approach has been widely used in order to constrain uncertainties in global quantities (e.g., Allen and Ingram 2002; Huber et al. 2011; Fasullo and Trenberth 2012; Sherwood et al. 2014; Masson and Knutti 2013; Millar et al. 2015; Tian 2015; Tan et al. 2016; Su et al. 2014; Klein and Hall 2015) as well as regional changes associated with local feedbacks and processes (e.g., Holland and Bitz 2003; Boé et al. 2009; Son et al. 2010; Schaller et al. 2011; Mahlstein and Knutti 2012; O'Gorman 2012; Massonnet et al. 2012; Cox et al. 2013; Wenzel et al. 2016; Loeb et al. 2016; Stegehuis et al. 2013; Hall and Qu 2006). In a broader sense, this approach reweights models, or recalibrates an ensemble in both mean and spread based on observations that demonstrably relate to the projection of interest. While combining and weighting models is not straightforward (Weigel et al. 2010; Knutti et al. 2010), it becomes increasingly difficult to justify a blind model democracy in which every model is treated equally, given the large differences in performance and the fact that models are often not independent of each other (Knutti et al. 2013; Tebaldi and Knutti 2007; Knutti 2010; Sanderson et al. 2015a). If all models are treated equally, large disagreement across models may hinder the assessment of climate change impacts.

We perform our analysis on the phase 5 of the Coupled Model Intercomparison Project (CMIP5) ensemble to evaluate models and produce calibrated ensembles. We refer to "calibration" or "constraining" as the selection of a small subset of models from the full ensemble according to a meaningful performance metric that can be observed. Estimation of the present-day response from observations is challenging as these are not always accurate or complete, in particular in the polar regions. The underlying assumption is that models with a low presentday bias relative to the observed climate are more likely to have a better representation of local processes and feedbacks, which is a requirement for projections to be reliable. Currently, it is not well understood how to use these relationships in an aggregate sense on different temporal scales to reduce the spread across models in an optimal way. Hence the goal of this study is to address two points that have so far received little attention. The first is to quantify the uncertainty in changes in projected temperature variability by combining observations with emergent relationships across models. The second is to quantify the improved agreement across models as a result of the emergent constraints method and its dependence on different choice of performance metrics, seasons, and time horizons used for the constraints.

\section{Data and methods}

\section{a. Datasets}

This study uses the recent compilation of coordinated model experiments - phase 5 of the Coupled Model Intercomparison Project (Taylor et al. 2012). We use monthly output for sea ice and surface air temperature from 40 models (see Table S1 in the online supplemental material). The analysis is performed for seasonal and yearly means for representative concentration pathway (RCP) 8.5 and 4.5. Models are evaluated against 2-m temperature from ERA-Interim (Dee et al. 2011) and NCEP-DOE Reanalysis 2 (Kanamitsu et al. 2002). The Hadley Centre Sea Ice and Sea Surface Temperature (HadISST) observational dataset (Rayner et al. 2003) is used to evaluate sea ice concentration. The present day is defined as a 35-yr period from 1979 to 2013 . The output from all models and datasets is regridded onto a $2.5^{\circ} \times 2.5^{\circ}$ grid to allow for gridpoint model comparison. The 
metrics selected for the analysis are the mean sea ice concentration and variability of temperature and of sea ice concentration. Variability fields (estimated as variance) are calculated at each grid point after linearly detrending the data for the time intervals of interest. The sea ice edge is the perimeter of the sea ice extent, defined as the total area of the grid cells with at least $15 \%$ sea ice concentration. The HadISST mask is then applied to all model fields to limit our analysis to where observations of sea ice exist. Grid points for which the sea ice mask differs across models are omitted (e.g., the area around the Canadian Archipelago may have different partitioning of land and ocean, in particular after regridding onto the common grid). Each model is given the same weight initially and we only use the first initial condition ensemble member for each model. We analyze the 35-yr time period centered around a global mean warming of $2^{\circ} \mathrm{C}$ relative to $1979-2013$.

\section{b. Model selection and types of constraints}

Model selection is performed separately for the Arctic (north of $60^{\circ} \mathrm{N}$ ) and the Antarctic areas (south of $60^{\circ} \mathrm{S}$; see the online supplemental material). On the gridpoint scale we calculate the squared difference between the model and the observational estimate for each of the metrics. The gridpoint biases are normalized by subtracting the ensemble mean and dividing by the standard deviation of the full ensemble. The model performance is defined as the area-weighted mean of the bias field, representing model skill for the metric at hand. Model biases from individual metrics are either used directly to select the best performing models to constrain projections of interest (narrow constraints) or aggregated further into a compound bias (broad constraints). Compound biases are obtained by summing these individual biases across seasons or metrics depending on the type of the constraint (see Fig. 5). [For example, the final subset of models as used for Fig. 1 or Fig. 4 sums up biases across all seasons and metrics (Fig. 5a) prior model selection. The exact combination for a specific constraint is specified in Fig. 5.]

In the next step, the models are sorted such that the model with the lowest overall bias is ranked first, and is considered to be the best model. We pick the best five models for the constrained projection. If within this subset there are models developed by the same center, the second best model from the repeated center is dropped from the list, and the next model is added from the full list. The final five models from five modeling centers (there are 17 centers in our analysis; see section 5 for details) are then selected.

\section{c. Strength of the constraint}

In the context of this work, the strength of the constraint is a measure to quantify how much tighter the projection has become as a result of the constraint. First, we quantify the spread of the constrained and the full ensembles in terms of a standard deviation across the set of the models at each grid point. The ratio between the standard deviations is a measure of the relative improvement and provides an estimate of the strength of the constraint. High reduction in the spread over a large area corresponds to a highly constrained field. A value of 1 corresponds to no change in spread between the constrained and the full ensembles. We bin all the grid points according to this ratio (constrained spread divided by the full ensemble spread) in histograms. The vertical axis on those indicates the total area (contributions to which may come from grid boxes far apart) over which the corresponding change in spread was observed. As a reference, we compare the constrained ensemble to the spread reduction that would result from random selection of five models. Those histograms are computed by taking an average of 500 histograms that result from random selection of models. While allowing for one model per model center in the model subset, we define the overall "reduction in spread" as a fractional improvement between medians of the two histograms (median of the blue histogram minus median of the gray histogram, normalized by the median of the gray histogram in Fig. 4).

\section{Changes in temperature variability at high latitudes and link to sea ice}

We analyze the multimodel mean change in temperature variability in response to a global mean temperature increase of $2^{\circ} \mathrm{C}$ within each individual model (usually middle to late twenty-first century), relative to the present day. The left column of Fig. 1 shows the model mean responses prior to constraining. In the polar regions, the magnitude and the sign of the changes are different across seasons and locations. Large discrepancies across models are depicted by the small stippled area (regions where $80 \%$ of models agree on the sign of change). The sea ice cover is known to exert a strong influence over the atmosphere above it. The CMIP5 models exhibit large biases in sea ice cover in both hemispheres (Flato et al. 2013), so these biases in the sea ice are likely to be a major contributor to the uncertainties at high latitudes (e.g., Bracegirdle and Stephenson 2013; Bracegirdle et al. 2015). Nevertheless, the decrease in temperature variability is robust over the areas of sea ice retreat on annual and seasonal scales except for the local summer (Fig. 1, left column). The existence of sea ice acts as a barrier that prevents or reduces exchange of heat, momentum, and water between atmosphere and ocean, and hence modulates the temperature variability at the surface (Maykut 1978; 


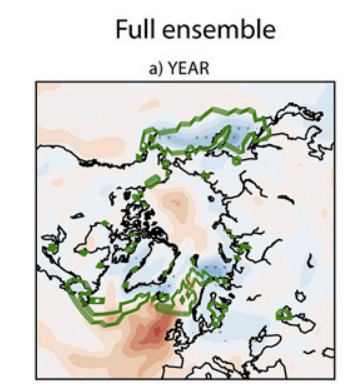

Constrained ensemble b) YEAR
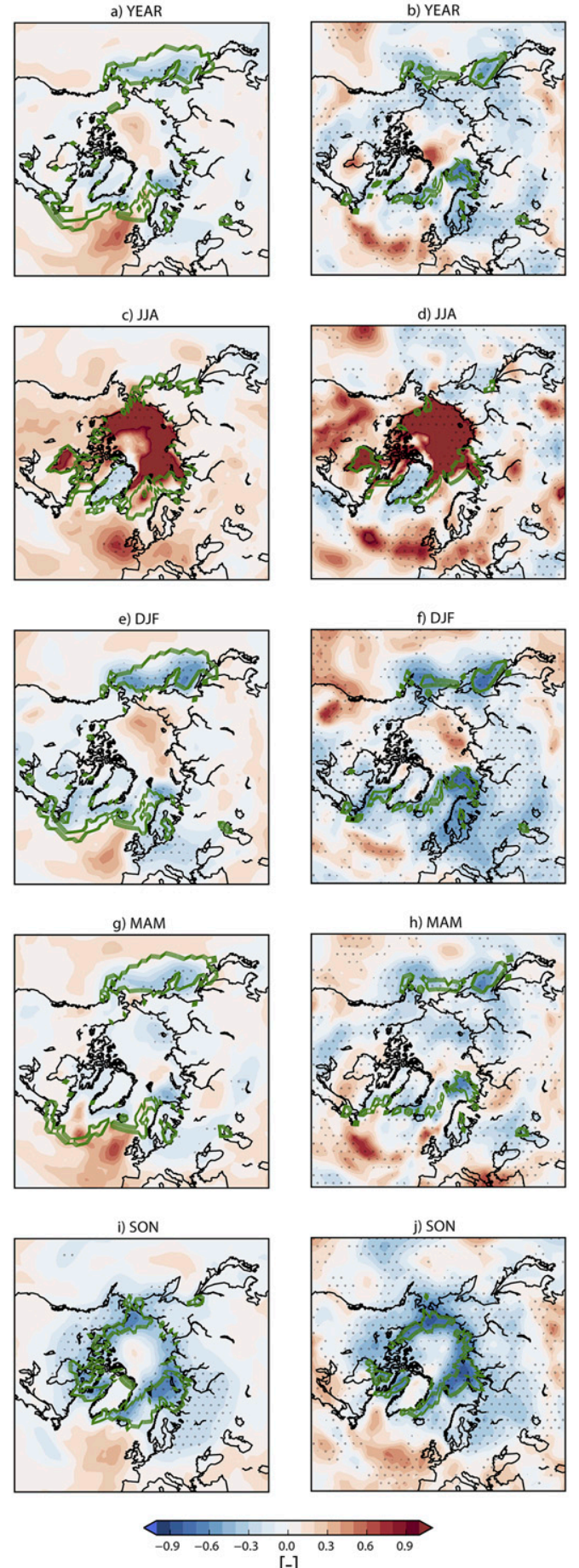

$[-]$

FIG. 1. Multimodel mean change in interannual temperature variability under RCP 8.5 at $2^{\circ} \mathrm{C}$ warming for the Arctic region relative to present-day variability (1979-2013) for annual mean and the four seasons. Calibrated projections based on the bestperforming models (making use of all the metrics available across seasons) are presented in the right column for direct comparison. The green line shows the area where at least $66 \%$ of the models that have sea ice cover become sea ice free. Sea ice-covered regions are defined where the fraction of sea ice exceeds $15 \%$. Stippling marks areas where $80 \%$ of models agree on the sign of change.
Overland et al. 2011; Vihma 2014; Kurtz et al. 2011; Serreze and Barry 2011). As the sea ice retreats permanently (grid cells where sea ice does not recover), it leaves open ocean with higher heat capacity which will tend to make the temperature less variable, leading to a decrease in temperature variability.

We explore differences in the magnitude of temperature and sea ice variability over open ocean and sea icecovered areas in the present-day climate, shown in Fig. 2. We do so by following the sea ice edge in each model and computing the median value of sea ice and temperature variability along the grid points at a given distance from the sea ice edge (e.g., one grid point north or south). In all seasons with the exception of the local summer, temperature and sea ice variability are high at locations close to the sea ice edge. Note that in the summer season at locations where partial sea ice cover exists, temperature variability is low. This is because the melting of the sea ice feeds waters that are at $0^{\circ} \mathrm{C}$ temperature, maintaining a surface temperature constant at near $0^{\circ} \mathrm{C}$. In the other seasons variability is substantially higher over the sea icecovered grid boxes than over the neighboring open ocean grid boxes. Figure 2 highlights that the magnitude of temperature variability and sea ice variability are tightly linked to the local fraction of sea ice cover. This coupling occurs at the surface through turbulent (sensible and latent heat) and radiative (shortwave and longwave radiation) fluxes, which are responsible for the thermodynamic exchange on the interface between the sea ice, ocean and the overlaying atmosphere (Serreze and Barry 2011; Kurtz et al. 2011; Bintanja and van der Linden 2013).

Existing studies showed that the partitioning of surface fluxes exhibits a clear seasonality and can provide insights into the interactions among the atmosphere, the sea ice, and the ocean (Blackport and Kushner 2016; Deser et al. 2010). The sea ice loss is greatest in summer and autumn. But the net energy flux (dominated by turbulent flux) into the atmosphere peaks in winter when the temperature difference between surface and atmosphere is largest (Deser et al. 2010). Because surface fluxes communicate the changes in sea ice cover to the atmosphere, the atmospheric response to sea ice loss is largest in winter (e.g., Screen and Simmonds 2010). In winter, low-level temperature inversions associated with stable atmospheric conditions usually occur over sea-ice- or snow-covered areas and are important for the surface energy partitioning (Deser et al. 2010; Zhang et al. 2011). Models tend to overestimate the amplitude of low-level inversions (i.e., temperature difference between surface and atmosphere is too large) and thus the stability of atmospheric boundary layer over sea ice-covered areas (Medeiros et al. 2011), which inflates the atmospheric 


\section{Northern Hemisphere}
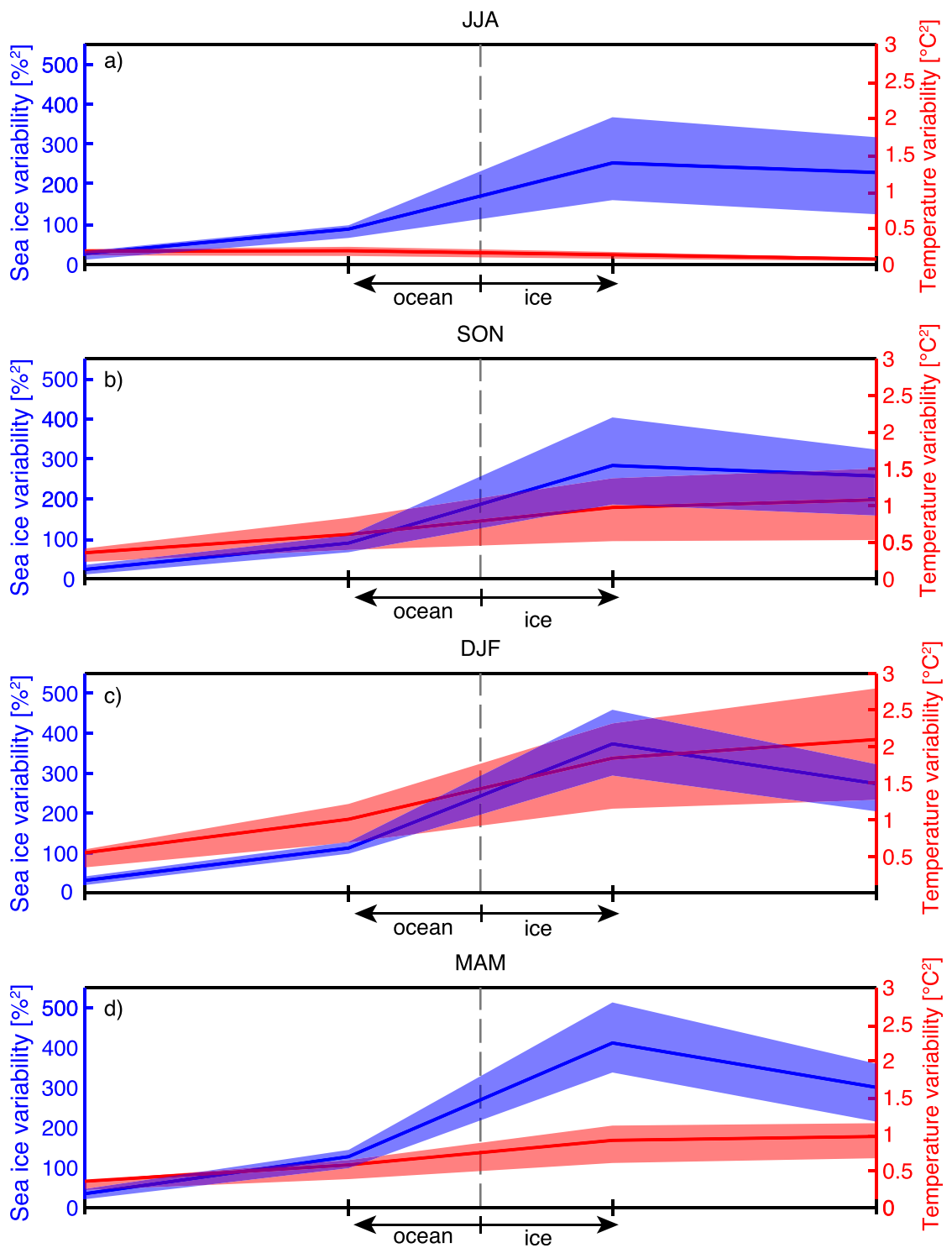

FIG. 2. Medians of sea ice variability (blue) and temperature variability (red) averaged latitudinally following the sea ice edge (gray) for the four seasons in the present day (19792013 ) in the Arctic region. The sea ice edge is defined as the border within each model where the fractional sea ice exceeds $15 \%$ averaged over the period. The horizontal axis marks individual grid boxes around the sea ice edge. The shaded area corresponds to the interquartile range from the multimodel ensemble.

response in models to sea ice retreat (Deser et al. 2010). The mismatch in timing between atmospheric response and the sea ice retreat implies that to disentangle the exact mechanism providing the link between the metrics in the present day and changes in temperature variability (i.e., to explain Fig. 2) would require an in depth analysis of the surface heat fluxes and their seasonality, which is beyond the scope of this work. At the same time, the air temperature above the sea ice can be influenced by large-scale circulation, which is uncertain in models and can further complicate the analysis.

Next, we relate long-term changes in sea ice cover, temperature, and sea ice variability. For the discussion we focus on the September-November (SON) season in the Arctic region, where we can classify the changes into three regimes. The first regime occurs in the proximity of the sea ice edge where areas with thin and highly variable sea ice experience a transition to open ocean 
with climate change, leading to a decrease in temperature and sea ice variability. The magnitude of the decrease for a single model is related to the initial availability of sea ice in that model, leading to strong positive correlations across models around the existing sea ice edge (top row in Fig. 3; this is also evident from Fig. 2b). The second regime occurs at locations where perennial sea ice cover is thinning with climate change but does not completely disappear (usually closer to the center of the Arctic). The temperature variability will increase along with the sea ice variability due to newly experienced year-to-year transitions between sea ice and open ocean. The third regime occurs if a particular model experiences a drastic local retreat from perennially ice-covered to perennially ice-free conditions, as it happens in some models showing a complete disappearance of the autumn Arctic sea ice by the end of the twenty-first century. Hence the changes in sea ice and temperature variability will be smaller in magnitude than in the other two regimes, as the condition with partial sea ice is not being experienced. The link between long-term changes of sea ice cover, sea ice variability, and temperature variability is evident in individual models (not shown). Hence at locations where the majority of the models show a shift from yearto-year varying sea ice coverage to open ocean (as in locations close to the sea ice edge) or from perennially sea ice free to year-to-year variable (as it occurs close to the pole during the Arctic winter; not shown), correlations between changes in sea ice cover, temperature variability, and sea ice variability are remarkably high (Fig. 3, top row). These correlations across models are lower if the models disagree on the local "regime"- that is, the relationships may not be as linear, but this does not imply that long-term changes in these metrics are unrelated or nonphysical.

We discussed above the existing physical relationship between the sea ice cover and the magnitude of sea ice and temperature variability in the present day, and for long-term changes. Hence, we expect a tight link between the magnitudes of the present day and their corresponding long-term changes (bottom row in Fig. 3). This essentially constitutes the emerging relationships later used to constrain projections. We first examine locations close to the multimodel mean sea ice edge in the present day. Locally, models that have very little sea ice will project small or no changes in temperature variability. On the contrary, models that have a large amount of sea ice at the same location will project a large decrease in temperature variability during the transition to open ocean conditions. This behavior in the proximity of sea ice edge leads to negative correlations between changes in temperature variability and present-day sea ice concentration (Fig. 3e), present-day sea ice variability (Fig. 3f), or present-day temperature variability (Fig. 3d).

At locations closer to the center of the Arctic, the sea ice cover is perennial (low sea ice variability by definition) and hence models exhibit lower temperature variability than close to the sea ice edge. With sea ice retreat and local thinning models may show an increase in temperature variability as the magnitude of sea ice variability is increasing. This will lead to positive correlations between the present-day sea ice cover and temperature variability change (Fig. 3e). Correlations between the present-day temperature variability and the magnitude of changes in temperature (Fig. 3d) and sea ice variability are negative (Fig. 3f). It is remarkable that the correlations are so high at the gridpoint scale in the SON season. Correlations in other seasons are lower because sea ice cover retreat does not occur at the same rate (Cavalieri and Parkinson 2012), but are still strong.

\section{Selection of metrics and models for emergent constraints}

Emergent constraints require evaluation of models based on performance metrics that can be adequately observed. In principle, there are an infinite number of performance metrics that can be defined from the model output. However performance in these metrics is often not related to the predictive skill within a model (e.g., Pincus et al. 2008; Reichler and Kim 2008; Pierce et al. 2009). Given the widespread availability of simulation data from multimodel ensembles, an exhaustive search through all possible combinations may result in spurious correlations between present-day metrics and projections simply by chance (Knutti et al. 2010; Masson and Knutti 2013; Caldwell et al. 2014). Existing studies highlight that models developed by the same institution often share parameterizations and code structure, leading to similarities in the output (Pennell and Reichler 2011; Masson and Knutti 2011; Knutti et al. 2013; Sanderson et al. 2015a,b; Abramowitz and Bishop 2015). One of the most obvious dependencies is between the simulations of the same model run at different resolutions (e.g., MPI-ESM-LR and MPI-ESMMR) or with different configurations (MIROC-ESM and MIROC-ESM-CHEM). Ignoring the presence of duplicate models in the ensemble may lead to an overestimation of model agreement and exaggerated spread reduction across the selected models after applying emergent constraints. Models from different centers may also share parameterization schemes; however, those similarities across models are more difficult to trace and would require an additional assessment that is beyond the scope of this work. 

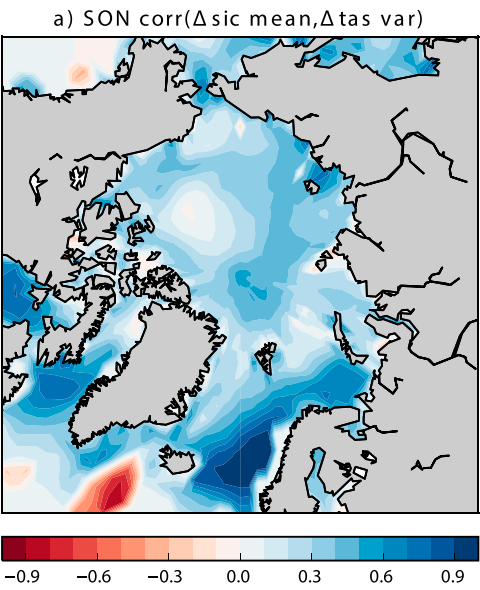

d) $\operatorname{SON} \operatorname{corr}(\Delta$ tas var,tas var)

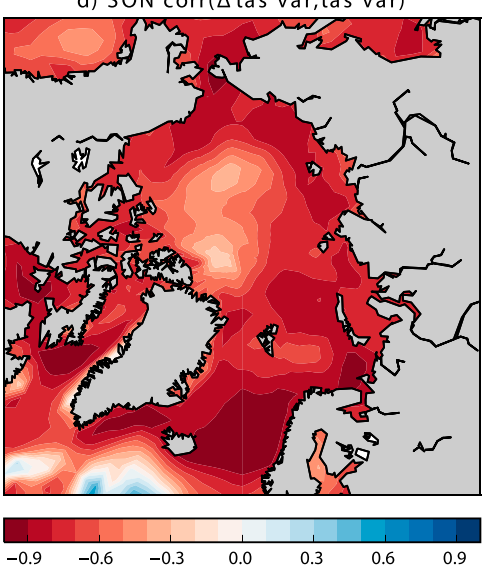

b) $\operatorname{SON} \operatorname{corr}(\Delta$ sic var, $\Delta$ tas var)
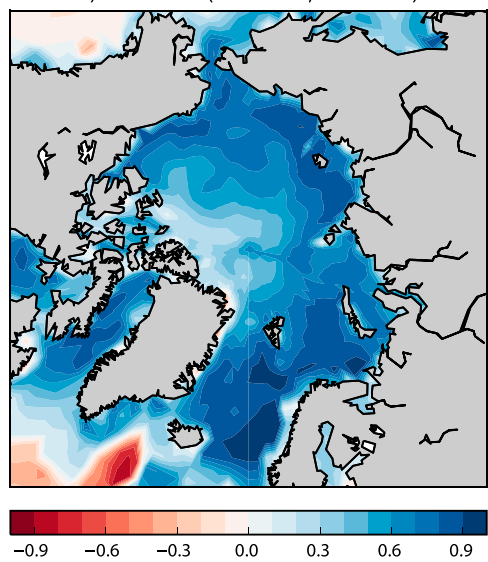

e) SON $\operatorname{corr}(\Delta$ tas var,sic mean)

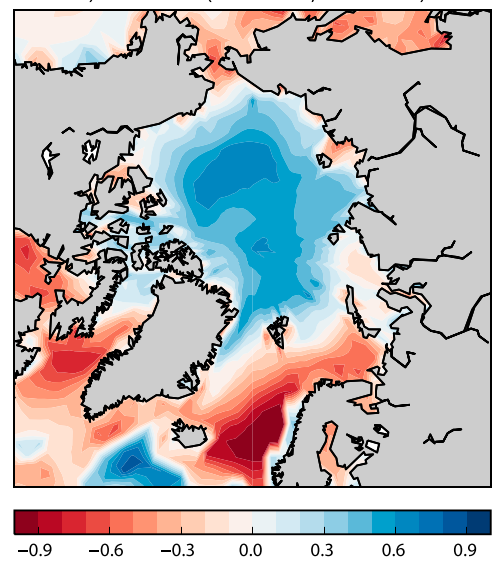

c) $\operatorname{SON} \operatorname{corr}(\Delta$ sic mean, $\Delta$ sic var)
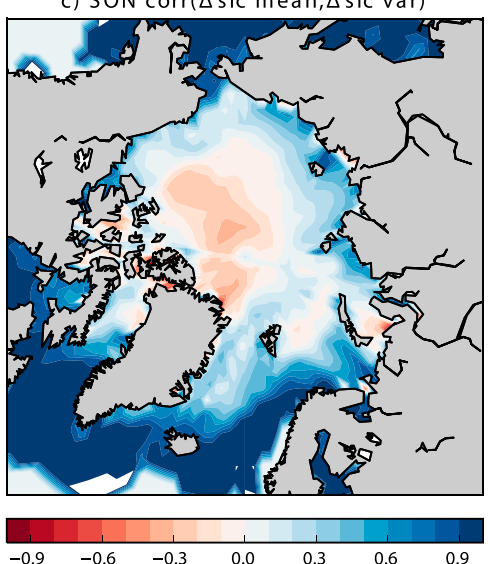

f) $\operatorname{SON} \operatorname{corr}(\Delta$ tas var, sic var)

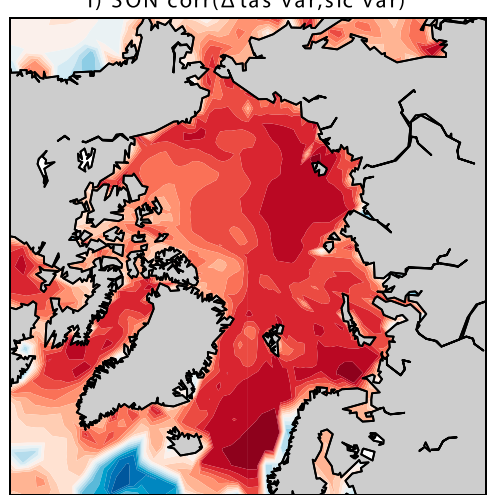

$\begin{array}{lllllll}-0.9 & -0.6 & -0.3 & 0.0 & 0.3 & 0.6 & 0.9\end{array}$

FIG. 3. Gridpoint correlations in the SON season between long-term changes (between $2^{\circ} \mathrm{C}$ warming and the present day) in (a) sea ice concentration and temperature variability, (b) sea ice variability and temperature variability, and (c) sea ice concentration and sea ice variability. Also shown are gridpoint correlations between long-term changes in temperature variability (at $2^{\circ} \mathrm{C}$ warming) and present-day (d) temperature variability, (e) sea ice concentration, and (f) sea ice variability.

In the presence of the abovementioned peculiarities in how CMIP5 is collected, a statistical relationship found between a present-day metric and projections requires a convincing physical explanation. In this study we use sea ice average and variability of sea ice and temperature as our metrics of choice. These are related in a physical way as is discussed in the earlier sections, so the possibility of spurious relationships is reduced. The exclusion of multiple models from one center in the constrained subsets also reduces the risk of overconfidence. Metrics of local sea ice trends are not used because it is not clear how (and whether) they relate to the future temperature variability. At the same time trends are in most cases not robust on local scales due to large internal variability during the brief time period with highquality observations (e.g., Deser et al. 2012; Swart et al. 2015).

The role of internal variability can be large for the metrics and time scales analyzed (Wettstein and Deser
2014; Swart et al. 2015; Mitchell et al. 2016). Large internal variability can prevent robust estimation of the present-day metrics as it can hide the true model response. Using a 20-member initial condition CESM ensemble, we find that the spread across the CESM ensemble for each of the present-day metrics is substantially smaller than of the CMIP5 ensemble (not shown). Internal variability is larger for the temperature variability metric than for any other of the metrics. However, if the role of internal variability were limiting, then we would expect to see no reduction model spread, as well as only weak correlations between present-day metrics and future changes.

Model selection is often hampered by the quality and availability of observations (for sea ice metrics) and reliability of reanalyses (for the temperature variability metric). A good estimate of the performance metrics from the observed climate is important for model evaluation. Otherwise a large observational uncertainty will 
lead to inconclusive results. For instance, the sea ice extent is relatively well observed since the satellite era (e.g., Alexeev et al. 2012). However, observations of the near-surface temperatures in the polar regions are very sparse and temperature is difficult to measure accurately in sea ice-covered regions (e.g., Jones 2016). Hence we use reanalysis data to estimate present-day temperature variability response (ERA-Interim and NCEP-DOE Reanalysis 2) because of the full coverage and higher reliability as physical consistency between temperature and sea ice fields is insured. Discrepancies between reanalyses at high latitudes are a known issue (Jakobson et al. 2012; Lindsay et al. 2014), usually attributed to the inhomogeneity of assimilated data and the method of assimilation (Thorne 2008; Grant et al. 2008; Bitz and Fu 2008; Screen and Simmonds 2011) as well as a poor understanding of relevant processes (Chung et al. 2013; Alexeev et al. 2012). The data assimilation procedure used in the development of reanalyses products usually prescribes sea ice field concentrations. The sea ice thickness, however, is not directly incorporated in this process as it is poorly observed and existing point measurements are difficult to translate to area-averaged values due to their highly heterogeneous nature (Kwok et al. 2009; Lindsay and Schweiger 2015). This could feed into disagreement in temperature variability across reanalyses as the atmosphere is in part modulated by the local properties of sea ice. The agreement between reanalyses on temperature variability estimate, to some degree, is an indication that the assimilated data constrain the atmospheric response. But it is important to emphasize that although agreement between reanalyses improves our confidence in the estimate, is cannot guarantee that it is accurate. This highlights the importance of developing reliable observational networks.

Perfect agreement across reanalyses is not required for the model selection procedure, but the choice of the reanalysis product should not result in a very different subset of models being selected. For the Arctic region, the model subset using an alternative reanalysis retains four out of five modeling centers. The selection of models for the final constrained ensemble (as in Fig. 1) is completely unaffected. This is not the case for the Antarctic region (see the online supplemental material). This is a showcase where limitations of observational datasets can be limiting a proper evaluation of models.

\section{Calibrated projections of temperature variability}

The best five models are selected from the full ensemble based upon their agreement with observations.
This number is a subjective choice but is a compromise between the total number of models (17 modeling centers) available and a sufficient number of models needed to sample the uncertainty of the calibrated ensemble. We emphasize that after removal of obvious model duplicates (e.g., models run at different resolution) we are left with a significantly smaller subsample of models than the full CMIP5 ensemble. Each model essentially represents one modeling center. The qualitative results (further discussed in the next section) do not depend on the ensemble size (sensitivity was tested with seven and eight models from distinct modeling centers; not shown) so the overall results based on subsets of five model ensembles are robust. Model evaluation results in different subsets of models being selected for the Arctic and Antarctic as different processes dominate local climates.

The five best performing models in sea ice average and temperature and sea ice variability are used to quantify the magnitude of changes in temperature variability. In the Arctic region in all seasons with exception of the local summer, the constrained ensemble projects a decrease in the magnitude of temperature variability. The magnitude of the decrease from the constrained ensemble (right column of Fig. 1) is larger than from the full ensemble (left column of Fig. 1) due to a more pronounced sea ice decline (not shown). For the Arctic region, these results are in agreement with earlier studies that found some of the CMIP models to underestimate the sea ice retreat in recent years and the future (Boé et al. 2009; Stroeve et al. 2012; Mahlstein and Knutti 2012; Flato et al. 2013). The Arctic temperature variability in the summer season is projected to increase (Fig. 2c) along with decreasing sea ice. In the present day, most of the heat is used to melt the existing sea ice, maintaining a surface temperature near $0^{\circ} \mathrm{C}$. The retreat of the sea ice will leave exposed open ocean waters and allow temperature to vary somewhat more (Bintanja and van der Linden 2013), thereby resulting in increasing temperature variability.

The constrained projections show higher agreement among its members than the whole range of CMIP5 models. This results in larger stippled areas in Fig. 1, indicating that most models in the constrained ensemble agree on the sign of the temperature variability change even farther away from the areas surrounding the sea ice. Nevertheless, these results should be interpreted with caution. The strong link between present-day metrics and the future change in temperature variability is limited to the sea ice surrounding areas, and hence it is not clear whether the calibrated ensemble has better skill at lower latitudes. Recently there have been an increasing number of studies suggesting the increasing importance of sea ice retreat on weather patterns at lower latitudes (Overland and Wang 2010; Overland et al. 2011; Cohen et al. 2012; 
Francis and Vavrus 2012; Vihma 2014; Tang et al. 2013), through changes in atmospheric circulation. However, process understanding of these remote impacts is hindered by large uncertainties in midlatitudinal atmospheric response to sea ice loss (Screen et al. 2014; Vihma 2014; Cohen et al. 2014). We therefore cannot make a strong statement about the skill of models at lower latitudes as the emergent constraint methodology requires a more thorough understanding of relevant underlying processes.

\section{Different types of constraints}

We show that using observations as constraints can lead to a narrower spread across the selected models than across the full ensemble. In this section we discuss the prerequisites for strong constraints and what factors could inhibit robust model evaluation. In principle, strong correlations between the current conditions and changes into the future imply that reduction in spread across models is achievable. A clear physical explanation for the observed link must exist to justify the use of the constraint. A larger signal in the system is expected to lead to a stronger correlation, as it allows the signal to emerge more clearly from the natural variability. Low observational uncertainty and agreement across observational datasets are mandatory for model selection not to be ambiguous. These aspects have to be considered for individual metric prior model evaluation.

Because we evaluate several metrics for different seasons (see below), the challenge is to robustly aggregate this information in order to gain the highest possible reduction in model spread. We repeat this analysis for the RCP4.5 scenario (not shown) and for the Antarctic region (in the online supplemental material) as a measure of robustness. In all cases, the qualitative results do not differ. To proceed, we make use of the current case study to explore a variety of different constraints. Conclusions and statements arising from this analysis should hold in other applications, as long the earlier stated aspects are considered. We have three metrics (sea ice average, interannual variability of temperature, and interannual variability of sea ice) available over five time scales (annual, JJA, DJF, MAM, and SON), allowing us to derive $15(5 \times 3)$ bias fields by comparing models with observations or reanalysis. In some cases, these individual biases are aggregated (by adding individual biases) across seasons and metrics to derive a compound bias to select models for the constrained projection of temperature variability changes at $2^{\circ} \mathrm{C}$ in four seasons and on annual time scales. How the aggregation of biases across seasons or metrics is performed is explained in section $2 b$. At this point, we make a distinction between broad and narrow constraining to explore the sensitivity of the results to the amount of information used for the constraint.

- Broad constraints: The first type uses information from all seasons and all metrics, resulting in one subset of models selected (Fig. 5a). The subset of models is then used for projections of changes in temperature variability for individual seasons. The second type uses information from all metrics within a season (Fig. 5b) for projections of changes in temperature variability of the same season. The third type aggregates information across all seasons but only for the one metric, resulting in three model subsets (Fig. 5c). These subsets of models are used to constrain projections of changes in temperature variability of individual seasons.

- Narrow constraints: This type does not aggregate information across seasons or metrics and uses individual metrics in individual seasons to constraint the respective quantity (15 subsets of models; Fig. 5d).

We first explore a broad constraint that aggregates information across all metrics and seasons for the Arctic region (Fig. 5a). The reduction in model spread due to such a constraint is substantial (green dots in Fig. 6a), except for summer. We expect this constraint to be more physically meaningful and better informed as it aggregates information across seasons and metrics. It is more likely to capture the relevant processes and feedbacks and thereby the relations across variables and seasons. In the case of model evaluation on individual seasons or single variables, the likelihood that the good agreement across models arises by chance is increased. Combining information across seasons ensures, for instance, that the seasonal cycle is more realistically represented, which likely implies a good physical representation of sea ice processes, increasing the confidence in the projections of the respective model.

The reduction in model spread for a broad constraint is aggregated in Fig. 4 (all metrics across all seasons; Fig. 5a). The histogram of the gridpoint improvement (expressed as a ratio, see methods section) after constraining is shown in blue, along with what is expected from random model subsets (gray). Detailed steps on how these histograms are constructed are provided in the methods section $2 \mathrm{c}$. In this example the histograms resulting from constraining are shifted toward smaller ratios relative to the histograms resulting from random selection of models. This shows that the reduction in spread is not by chance or from a smaller sample of models but rather because relevant information was extracted, resulting in an ensemble with a narrower projection. However, there is a danger in making the constraint too broad. As the number of metrics 

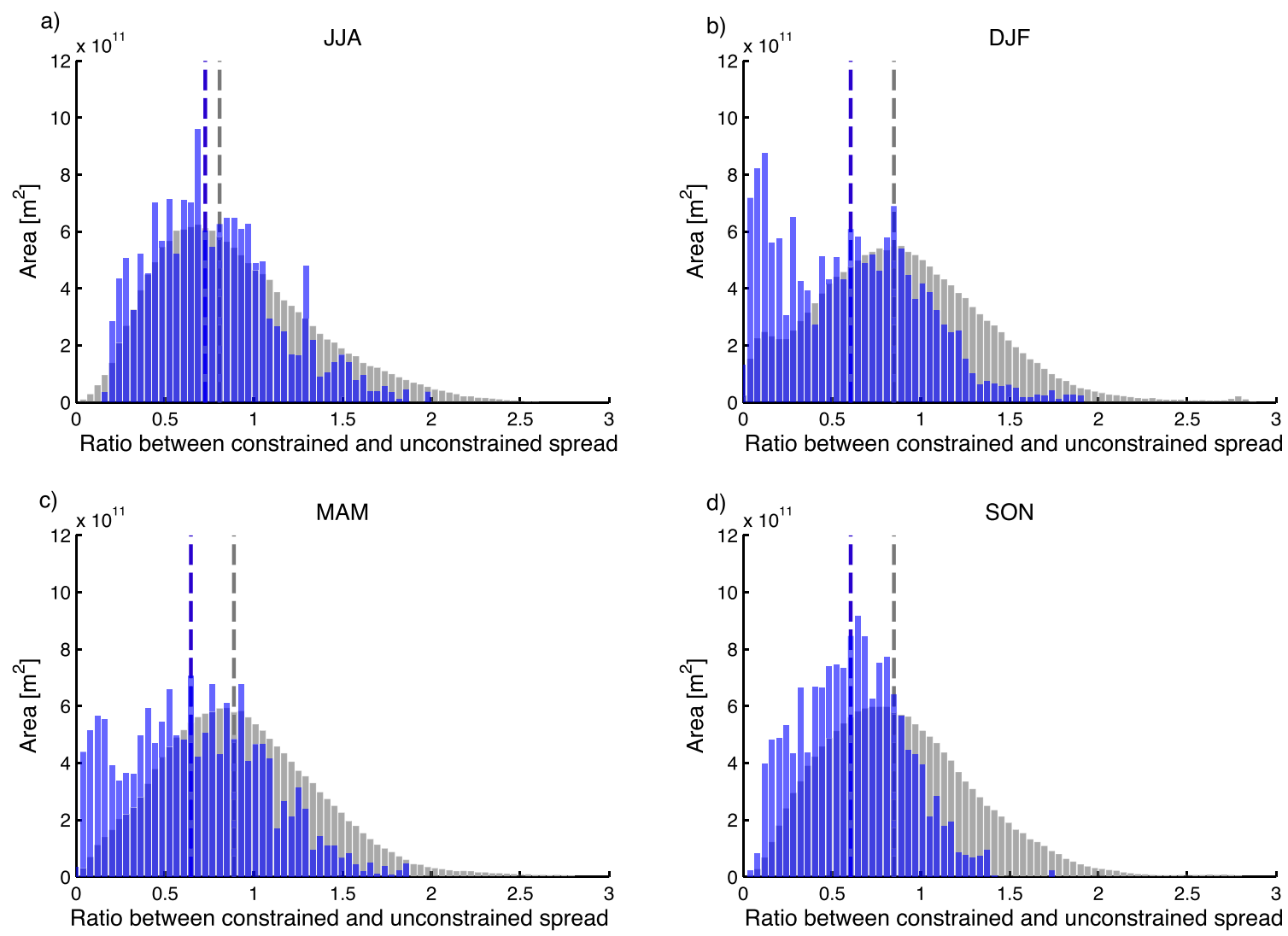

FIG. 4. Histograms illustrating the reduction in spread in temperature variability (as in Fig. 1) as a result of constraining the CMIP5 ensemble using constraints based on all metrics combined across all seasons. Gray histograms represent the ratios between the spread of a random subset of five models and the spread of the full ensemble, mimicking the case of no constraint. The blue histograms represent the same ratio after a broad constraint combining all metrics across all seasons and results in smaller values and narrower projections. The vertical lines mark the location of the median for each of the histograms.

increases, the final constrained ensemble range can be as wide as the full ensemble because the information from metrics that matter could be lost through the inclusion of other unrelated variables.

So do we actually need all the metrics aggregated across seasons included in our "broad" constraints to achieve the same reduction in spread across models? Using information from one season and one metric to constrain projections of temperature variability changes in the same season would be an example of a narrow constraint (red dots in Fig. 6a). This type of constraint can be effective for the season of interest (at times more so than the broad constraint in green in Fig. 6), but it fails to constrain changes in other seasons (not shown) as the information was omitted to begin with. Figure 6 (see also supplemental Fig. S3 for the Antarctic region) shows the reduction in spread in the constrained set relative to a random set of models for different constraints. It is quantified as a fractional improvement between medians of histograms - as in Fig. 4 (see methods) - with positive values indicating a smaller spread than resulting from random subset of models. The blue dots in Fig. 6a are a type of a broad constraint in which individual scores are aggregated across all metrics of one season (Fig. 5b) to constrain the season of interest. We see that this type of broad constraints (blue dots in Fig. 6b) is often not as effective as the constraint that aggregated all metrics across seasons (green dots in Fig. 6a). Although in some cases, narrow constraints (Fig. 5d; red dots in Fig. 6) could be more effective (higher reduction in model spread) than the broad ones, the result could lead to overfitting. An additional advantage of a broad constraint is that the fields for different seasons and metrics are physically consistent with each other as these come from the same subset of models, leading to easier interpretation.

The choice of the present-day metric matters for the constraints (Figs. 5b and S3b). Subsets of models selected from individual metrics are similar, but they differ enough to diverge on the magnitude of reduction of spread across its members. To some extent the overlap of selected models is expected since variables used for the constraint (sea ice average, sea ice variability, and 

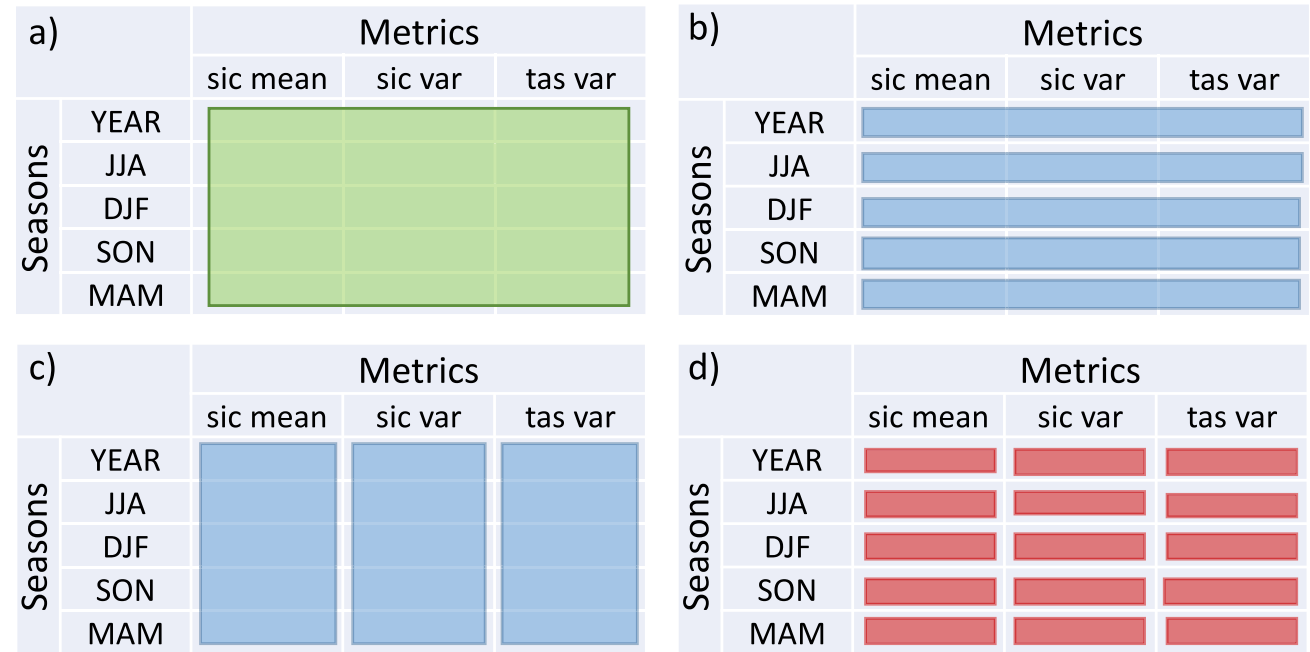

FIG. 5. Schematic illustrating aggregation of information across seasons and metrics, showing (a) a broad constraint that aggregates information across seasons and metrics; (b),(c) constraints that only aggregate information across metrics or seasons, respectively; and (d) narrow constraints with no aggregation.

temperature variability) are tightly linked. Thus, an accurate representation of one variable often implies a reasonable representation of other variables. Figure $6 \mathrm{~b}$ shows that constraints are often stronger if the metric of choice is combined across seasons (blue dots in Fig. 6b; three subsets of models) than if no aggregation is implemented (red dots in Fig. 6b). While different choices of the metrics (and how to combine these across seasons) yield somewhat different results, it is worth pointing out that uncertainties decrease no matter what metric is chosen (i.e., there is a value in using data to evaluate models). The concern that such a reduction in spread might arise by chance is not justified, as the relationships arise from physical processes. If the metric was unrelated to the prediction of interest, this would be equivalent to picking models randomly, which would result in a gray histogram similar to Fig. 4 and a value of zero in Fig. 6.

So far we have focused on relative changes of temperature variability at $2^{\circ} \mathrm{C}$ global warming. Therefore as a next step, we intend to capture the overall behavior of different types of constraints as a function of different warming targets $\left(0.5^{\circ}-2^{\circ} \mathrm{C}\right.$ global mean warming with respect to the present day). We also emphasize that the results may differ depending on the quantity at hand: the absolute values of future projections (Fig. 6c) or the magnitude of relative changes (Fig. 6d). Projections for both the change and the future absolute value can be considered for constraining as long as there is a physically justifiable correlation. The reduction in spread in the two cases depends on the time horizon. Constraining the absolute future state is largely an extrapolation of the present-day state. Accurate simulation of the present day within the model represents a strong predictor for the immediate future, and hence the effectiveness of the constraint decreases from lower to higher warming targets (Fig. 6c). To constrain the projected changes, the constraint is stronger for higher warming than lower targets because only then the climate change signal becomes large with respect to variability (Fig. 6d). The further away the target period is from the present day, the stronger the change is, leading to emergence of the constraint as the sea ice retreats. Note that the blue and red bars at $2^{\circ} \mathrm{C}$ warming target in Fig. $6 \mathrm{~d}$ encompass all the constraints from Figs. 5a and 5b (green dots are included in the blue bar). The broad constraints (blue bars) are stronger than the narrow constraint at higher warming targets. This could be because the interrelations between variables across seasons become important, and this is something that is unlikely to be captured by the narrow constraint as it only considers one season or one metric.

Nonetheless there is a limit by how much the spread across models can be reduced through sea ice-related metrics. Any type of constraint based on sea ice will saturate once the sea ice-covered regions become ice free. Hence the maximum change in temperature variability due to sea ice cover retreat is physically constrained by the sea ice availability at a grid point. Also, since the sea ice concentration at a grid point is bounded between 0 and $100 \%$, care should be taken when estimating the variability of sea ice cover. When we approach sea ice-free conditions, the transition from highly variable sea ice to open ocean will result in an abrupt change in sea ice variability. Hence the sea ice 
a) Relative changes at $2 \mathrm{C}$

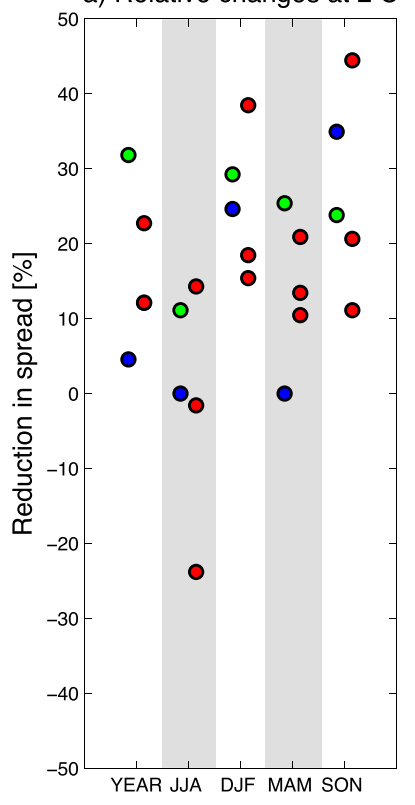

b) Relative changes at $2 \mathrm{C}$

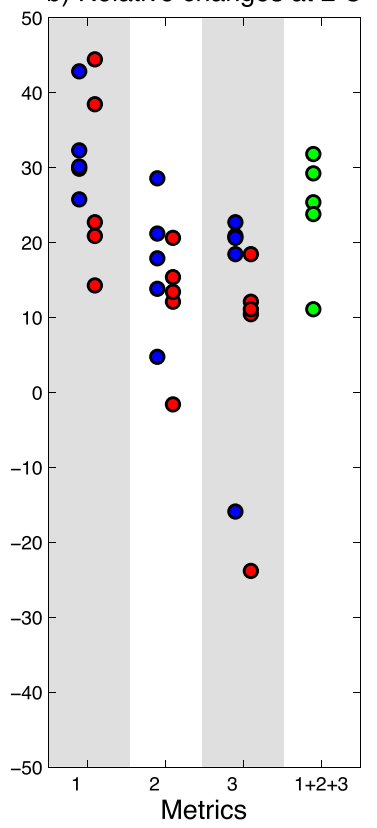

c) Absolute changes

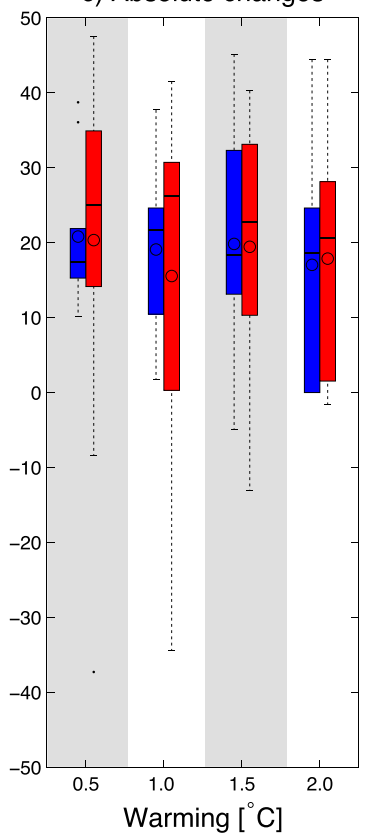

d) Relative changes

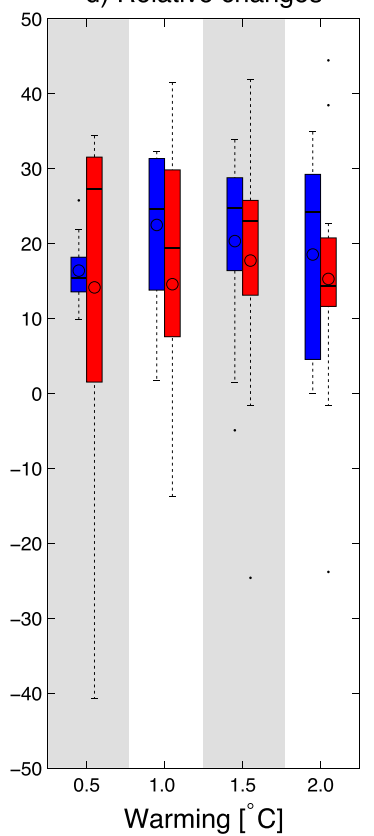

FIG. 6. Reduction in model spread as a result of different types of constraints for the Arctic region in the RCP8.5 scenario. Red dots indicate narrow constraints (i.e., no aggregation of information across seasons or metrics). Green dots are a type of broad constraint that aggregates information across all metrics and seasons. The blue dots are another type of broad constraints that aggregate information across (a) seasons and (b) metrics. Boxplots collect all combinations of narrow (red) and broad (blue) for a target warming level. Also shown are constraints on (c) the absolute values of the future temperature variability and (d) the relative change in temperature variability as a function of the warming. Box plots indicate the quartiles (edges of the box), 1.5 times the interquartile range (whiskers), the mean (circle), and outliers (black dots) of the strength of the constraint (defined in the methods section): higher values indicate a stronger reduction in spread over larger areas, and smaller ranges indicate robustness of constraint (i.e., less sensitivity to the exact combination of metrics); see text for details.

variability estimates become more uncertain close to those limits, when a linear detrending of a nonlinear transition is no longer meaningful.

\section{Summary and conclusions}

We examined the uncertain changes in temperature variability at high latitudes in response to increasing global temperatures. We showed that the model spread can be traced back to the skill at simulating average present-day sea ice, and interannual variability of average sea ice and temperature. We found strong relations across models between these metrics and projected changes in interannual variability of seasonal (and annual) temperature as the sea ice retreats. We showed that the relations across these metrics in the present day and to future changes in temperature variability are consistent with the physical understanding of the Arctic climate. These relations across models are strongest in locations where models simulate a wide range sea ice amounts (i.e., around the sea ice edge). We then made use of these relations to constrain the range of projections of temperature variability by evaluating models with observational datasets and reanalyses (i.e., using emergent constraints). This is a widely used method that relates the bias between observational estimates and models to the magnitude of projections. Then the models were ranked based on this bias to determine their adequacy for projections of temperature variability and subsets of skillful models were picked. The selected subsample of models had a substantially smaller spread in projections across its members than the full ensemble. We explicitly quantified the reduction in spread across models, emphasizing the value of using emergent constraints.

In addition to the existence of physically plausible link between present day and projections, we highlight aspects that need to be considered when implementing this method. The role of internal variability needs to be substantially lower than the spread encountered across the full ensemble, otherwise model performance cannot be assessed. We further acknowledge that given lack of a dense observational network in polar and sea ice-covered regions, the reliability of our estimates based on reanalyses and observations is limited. If observational dataset or reanalysis would provide an erroneous estimate of the 
metrics used for model evaluation, it would result in an inaccurately constrained projection. To minimize this risk we have compared two different reanalysis products.

One of the challenges of this method arises due to presence of several metrics that are potentially relevant for projections of the target variable on different temporal and spatial scales. In this study we explored how the relevant information can be aggregated to achieve the highest reduction in spread across models and how robust the results are toward those choices. We showed that emergent constraints almost always result in a reduction in model spread, highlighting the value of using this approach. The magnitude of the reduction in model spread depends on the relevance of a particular metric for the projection of interest, as well as how different metrics are aggregated. A large reduction in spread can be often achieved without the need of any aggregation, but there is also a danger of finding no improvement at all. In the current case study, models evaluated on individual metrics within one season were often found to have similar performance across metrics because these are not independent. This supports the idea that different variables are linked through processes, and hence that good performance in one is likely to result in good performance in other and in more reliable future projections. We found that a robust and more physically meaningful constraint can be obtained by combining information from all the key metrics across seasons, leading to a large reduction in spread across models. It is more likely that such aggregated constraint captures the important processes relevant for the overall future climate.

The choice of the metric to evaluate the models will to some degree always be subjective and depends on the questions at hand. But all choices tested performed clearly better than not using the observations to evaluate the models at all, and a documentation of how the results depend on the choices made can contribute to higher confidence in constrained projections.

Acknowledgments. We acknowledge the World Climate Research Programme's Working Group on Coupled Modelling, which is responsible for CMIP, and we thank the climate modeling groups (listed in Table $\mathrm{S} 1$ in the online supplementary material of this paper) for producing and making available their model output. For CMIP the U.S. Department of Energy's Program for Climate Model Diagnosis and Intercomparison provides coordinating support and led development of software infrastructure in partnership with the Global Organization for Earth System Science Portals.

\section{REFERENCES}

Abramowitz, G., and C. Bishop, 2015: Climate model dependence and the ensemble dependence transformation of CMIP projections. J. Climate, 28, 2332-2348, doi:10.1175/ JCLI-D-14-00364.1.

Alexeev, V. A., I. Esau, I. V. Polyakov, S. J. Byam, and S. Sorokina, 2012: Vertical structure of recent Arctic warming from observed data and reanalysis products. Climatic Change, 111, 215-239, doi:10.1007/s10584-011-0192-8.

Allen, M. R., and W. J. Ingram, 2002: Constraints on future changes in climate and the hydrologic cycle. Nature, 419, 224-232, doi:10.1038/nature01092.

Beniston, M., and D. B. Stephenson, 2004: Extreme climatic events and their evolution under changing climatic conditions. Global Planet. Change, 44, 1-9, doi:10.1016/j.gloplacha.2004.06.001.

Bintanja, R., and E. C. van der Linden, 2013: The changing seasonal climate in the Arctic. Sci. Rep., 3, 1556, doi:10.1038/srep01556.

Bitz, C. M., and Q. Fu, 2008: Arctic warming aloft is data set dependent. Nature, 455, E3-E4, doi:10.1038/nature07258.

Blackport, R., and P. J. Kushner, 2016: The transient and equilibrium climate response to rapid summertime sea ice loss in CCSM4. J. Climate, 29, 401-417, doi:10.1175/JCLI-D-15-0284.1.

Boé, J., A. Hall, and X. Qu, 2009: September sea-ice cover in the Arctic Ocean projected to vanish by 2100. Nat. Geosci., 2, 341-343, doi:10.1038/ngeo467.

Bracegirdle, T. J., and D. B. Stephenson, 2013: On the robustness of emergent constraints used in multimodel climate change projections of Arctic warming. J. Climate, 26, 669-678, doi:10.1175/JCLI-D-12-00537.1.

- _ - J. Turner, and T. Phillips, 2015: The importance of sea ice area biases in 21st century multimodel projections of Antarctic temperature and precipitation. Geophys. Res. Lett., 42, 10 832-10 839, doi:10.1002/2015GL067055.

Caldwell, P. M., C. S. Bretherton, M. D. Zelinka, S. A. Klein, B. D. Santer, and B. M. Sanderson, 2014: Statistical significance of climate sensitivity predictors obtained by data mining. Geophys. Res. Lett., 41, 1803-1808, doi:10.1002/2014GL059205.

Cavalieri, D. J., and C. L. Parkinson, 2012: Arctic sea ice variability and trends, 1979-2010. Cryosphere, 6, 881-889, doi:10.5194/ tc-6-881-2012.

Chung, C. E., H. Cha, T. Vihma, P. Räisänen, and D. Decremer, 2013: On the possibilities to use atmospheric reanalyses to evaluate the warming structure in the Arctic. Atmos. Chem. Phys., 13, 11 209-11 219, doi:10.5194/acp-13-11209-2013.

Cohen, J. L., J. C. Furtado, M. A. Barlow, V. A. Alexeev, and J. E. Cherry, 2012: Arctic warming, increasing snow cover and widespread boreal winter cooling. Environ. Res. Lett., 7, 014007, doi:10.1088/1748-9326/7/1/014007.

— , and Coauthors, 2014: Recent Arctic amplification and extreme mid-latitude weather. Nat. Geosci., 7, 627-637, doi:10.1038/ngeo2234.

Colle, B. A., Z. Zhang, K. A. Lombardo, E. Chang, P. Liu, and M. Zhang, 2013: Historical evaluation and future prediction of eastern North American and western Atlantic extratropical cyclones in the CMIP5 models during the cool season. J. Climate, 26, 6882-6903, doi:10.1175/JCLI-D-12-00498.1.

Cox, P. M., D. Pearson, B. B. Booth, P. Friedlingstein, C. Huntingford, C. D. Jones, and C. M. Luke, 2013: Sensitivity of tropical carbon to climate change constrained by carbon dioxide variability. Nature, 494, 341-344, doi:10.1038/nature11882.

Dee, D. P., and Coauthors, 2011: The ERA-Interim reanalysis: Configuration and performance of the data assimilation 
system. Quart. J. Roy. Meteor. Soc., 137, 553-597, doi:10.1002/ qj. 828.

Della-Marta, P. M., M. R. Haylock, J. Luterbacher, and H. Wanner, 2007: Doubled length of western European summer heat waves since 1880. J. Geophys. Res., 112, D15103, doi:10.1029/2007JD008510.

Deser, C., R. Tomas, M. Alexander, and D. Lawrence, 2010: The seasonal atmospheric response to projected Arctic sea ice loss in the late twenty-first century. J. Climate, 23, 333-351, doi:10.1175/2009JCLI3053.1.

— A. Phillips, V. Bourdette, and H. Teng, 2012: Uncertainty in climate change projections: The role of internal variability. Climate Dyn., 38, 527-546, doi:10.1007/s00382-010-0977-x.

— , R. A. Tomas, and L. Sun, 2015: The role of oceanatmosphere coupling in the zonal-mean atmospheric response to Arctic sea ice loss. J. Climate, 28, 2168-2186, doi:10.1175/ JCLI-D-14-00325.1.

De Vries, H., R. J. Haarsma, and W. Hazeleger, 2012: Western European cold spells in current and future climate. Geophys. Res. Lett., 39, L04706, doi:10.1029/2011GL050665.

Dutra, E., C. Schär, P. Viterbo, and P. M. A. Miranda, 2011: Landatmosphere coupling associated with snow cover. Geophys. Res. Lett., 38, L15707, doi:10.1029/2011GL048435.

Fasullo, J. T., and K. E. Trenberth, 2012: A less cloudy future: The role of subtropical subsidence in climate sensitivity. Science, 338, 792-794, doi:10.1126/science.1227465.

Fischer, E. M., and C. Schär, 2009: Future changes in daily summer temperature variability: Driving processes and role for temperature extremes. Climate Dyn., 33, 917-935, doi:10.1007/ s00382-008-0473-8.

_ J. Rajczak, and C. Schär, 2012: Changes in European summer temperature variability revisited. Geophys. Res. Lett., 39, L19702, doi:10.1029/2012GL052730.

Flato, G., and Coauthors, 2013: Evaluation of climate models. Climate Change 2013: The Physical Science Basis, T. F. Stocker et al., Eds., Cambridge University Press, 741-866.

Francis, J. A., and S. J. Vavrus, 2012: Evidence linking Arctic amplification to extreme weather in mid-latitudes. Geophys. Res. Lett., 39, L06801, doi:10.1029/2012GL051000.

$\longrightarrow$, and — 2015: Evidence for a wavier jet stream in response to rapid Arctic warming. Environ. Res. Lett., 10, 014005, doi:10.1088/1748-9326/10/1/014005.

Grant, A. N., S. Brönnimann, and L. Haimberger, 2008: Recent Arctic warming vertical structure contested. Nature, 455, E2-E3, doi:10.1038/nature07257.

Hall, A., and X. Qu, 2006: Using the current seasonal cycle to constrain snow albedo feedback in future climate change. Geophys. Res. Lett., 33, L03502, doi:10.1029/2005GL025127.

Holland, M. M., and C. M. Bitz, 2003: Polar amplification of climate change in coupled models. Climate Dyn., 21, 221-232, doi:10.1007/s00382-003-0332-6.

Huber, M., I. Mahlstein, M. Wild, J. Fasullo, and R. Knutti, 2011: Constraints on climate sensitivity from radiation patterns in climate models. J. Climate, 24, 1034-1052, doi:10.1175/ 2010JCLI3403.1.

Huntingford, C., P. D. Jones, V. N. Livina, T. M. Lenton, and P. M. Cox, 2013: No increase in global temperature variability despite changing regional patterns. Nature, 500, 327-330, doi:10.1038/nature12310.

Jakobson, E., T. Vihma, T. Palo, L. Jakobson, H. Keernik, and J. Jaagus, 2012: Validation of atmospheric reanalyses over the central Arctic Ocean. Geophys. Res. Lett., 39, L10802, doi:10.1029/2012GL051591.
Johannessen, O. M., and Coauthors, 2004: Arctic climate change: Observed and modelled temperature and sea ice variability. Tellus, 56A, 328-341, doi:10.1111/j.1600-0870.2004.00060.x.

Jones, P., 2016: The reliability of global and hemispheric surface temperature records. Adv. Atmos. Sci., 33, 269-282, doi:10.1007/s00376-015-5194-4.

Kanamitsu, M., W. Ebisuzaki, J. Woollen, S.-K. Yang, J. J. Hnilo, M. Fiorino, and G. L. Potter, 2002: NCEP-DOE AMIP-II Reanalysis (R-2). Bull. Amer. Meteor. Soc., 83, 1631-1643, doi:10.1175/BAMS-83-11-1631.

Kharin, V. V., F. W. Zwiers, X. Zhang, and M. Wehner, 2013: Changes in temperature and precipitation extremes in the CMIP5 ensemble. Climatic Change, 119, 345-357, doi:10.1007/ s10584-013-0705-8.

Kjellström, E., L. Bärring, D. Jacob, R. Jones, G. Lenderink, and C. Schär, 2007: Modelling daily temperature extremes: Recent climate and future changes over Europe. Climatic Change, $\mathbf{8 1}$, 249-265, doi:10.1007/s10584-006-9220-5.

Klein, S. A., and A. Hall, 2015: Emergent constraints for cloud feedbacks. Curr. Climate Change Rep., 1, 276-287, doi:10.1007/s40641-015-0027-1.

Knutti, R., 2010: The end of model democracy? Climatic Change, 102, 395-404, doi:10.1007/s10584-010-9800-2.

— and J. Sedláček, 2012: Robustness and uncertainties in the new CMIP5 climate model projections. Nat. Climate Change, 3, 369-373, doi:10.1038/nclimate1716.

—, R. Furrer, C. Tebaldi, J. Cermak, and G. A. Meehl, 2010: Challenges in combining projections from multiple climate models. J. Climate, 23, 2739-2758, doi:10.1175/2009JCLI3361.1.

_ D. Masson, and A. Gettelman, 2013: Climate model genealogy: Generation CMIP5 and how we got there. Geophys. Res. Lett., 40, 1194-1199, doi:10.1002/grl.50256.

Kretschmer, M., D. Coumou, J. F. Donges, and J. Runge, 2016: Using causal effect networks to analyze different Arctic drivers of midlatitude winter circulation. J. Climate, 29, 40694081, doi:10.1175/JCLI-D-15-0654.1.

Kurtz, N. T., T. Markus, S. L. Farrell, D. L. Worthen, and L. N. Boisvert, 2011: Observations of recent Arctic sea ice volume loss and its impact on ocean-atmosphere energy exchange and ice production. J. Geophys. Res., 116, C04015, doi:10.1029/ 2010JC006235.

Kwok, R., G. F. Cunningham, M. Wensnahan, I. Rigor, H. J. Zwally, and D. Yi, 2009: Thinning and volume loss of the Arctic Ocean sea ice cover: 2003-2008. J. Geophys. Res., 114, C07005, doi:10.1029/2009JC005312.

Lindsay, R., and A. Schweiger, 2015: Arctic sea ice thickness loss determined using subsurface, aircraft, and satellite observations. Cryosphere, 9, 269-283, doi:10.5194/tc-9-269-2015.

_-, M. Wensnahan, A. Schweiger, and J. Zhang, 2014: Evaluation of seven different atmospheric reanalysis products in the Arctic. J. Climate, 27, 2588-2606, doi:10.1175/ JCLI-D-13-00014.1.

Loeb, N. G., H. Wang, A. Cheng, S. Kato, J. T. Fasullo, K.-M. $\mathrm{Xu}$, and R. P. Allan, 2016: Observational constraints on atmospheric and oceanic cross-equatorial heat transports: Revisiting the precipitation asymmetry problem in climate models. Climate Dyn., 46, 3239-3257, doi:10.1007/ s00382-015-2766-z.

Mahlstein, I., and R. Knutti, 2012: September Arctic sea ice predicted to disappear near $2^{\circ} \mathrm{C}$ global warming above present. J. Geophys. Res., 117, D06104, doi:10.1029/2011JD016709.

Masson, D., and R. Knutti, 2011: Climate model genealogy. Geophys. Res. Lett., 38, L08703, doi:10.1029/2011GL046864. 
— , and - 2013: Predictor screening, calibration, and observational constraints in climate model ensembles: An illustration using climate sensitivity. J. Climate, 26, 887-898, doi:10.1175/JCLI-D-11-00540.1.

Massonnet, F., T. Fichefet, H. Goosse, C. M. Bitz, G. PhilipponBerthier, M. M. Holland, and P.-Y. Barriat, 2012: Constraining projections of summer Arctic sea ice. Cryosphere, 6, 1383-1394, doi:10.5194/tc-6-1383-2012.

Maykut, G. A., 1978: Energy exchange over young sea ice in the central Arctic. J. Geophys. Res., 83, 3646-3658, doi:10.1029/ JC083iC07p03646.

Medeiros, B., C. Deser, R. A. Tomas, and J. E. Kay, 2011: Arctic inversion strength in climate models. J. Climate, 24, 47334740, doi:10.1175/2011JCLI3968.1.

Millar, R. J., A. Otto, P. M. Forster, J. A. Lowe, W. J. Ingram, and M. R. Allen, 2015: Model structure in observational constraints on transient climate response. Climatic Change, 131, 199-211, doi:10.1007/s10584-015-1384-4.

Mitchell, D., and Coauthors, 2016: Assessing mid-latitude dynamics in extreme event attribution systems. Climate Dyn. 1-13, doi:10.1007/s00382-016-3308-z.

O'Gorman, P., 2012: Sensitivity of tropical precipitation extremes to climate change. Nat. Geosci., 5, 697-700, doi:10.1038/ngeo1568.

Overland, J. E., and M. Wang, 2010: Large-scale atmospheric circulation changes are associated with the recent loss of Arctic sea ice. Tellus, 62A, 1-9, doi:10.1111/j.1600-0870.2009.00421.x.

_ , K. R. Wood, and M. Wang, 2011: Warm Arctic-cold continents: Climate impacts of the newly open Arctic Sea. Polar Res., 30, 15787, doi:10.3402/polar.v30i0.15787.

_ - and Coauthors, 2016: Nonlinear response of mid-latitude weather to the changing Arctic. Nat. Climate Change, 6, 992 999, doi:10.1038/nclimate3121.

Peings, Y., and G. Magnusdottir, 2014: Response of the wintertime Northern Hemisphere atmospheric circulation to current and projected Arctic sea ice decline: A numerical study with CAM5 J. Climate, 27, 244-264, doi:10.1175/JCLI-D-13-00272.1.

Pennell, C., and T. Reichler, 2011: On the effective number of climate models. J. Climate, 24, 2358-2367, doi:10.1175/ 2010JCLI3814.1.

Pierce, D. W., T. P. Barnett, B. D. Santer, and P. J. Gleckler, 2009: Selecting global climate models for regional climate change studies. Proc. Natl. Acad. Sci. USA, 106, 8441-8446, doi:10.1073/pnas.0900094106.

Pincus, R., C. P. Batstone, R. J. P. Hofmann, K. E. Taylor, and P. J. Glecker, 2008: Evaluating the present-day simulation of clouds, precipitation, and radiation in climate models. J. Geophys. Res., 113, D14209, doi:10.1029/2007JD009334.

Rayner, N. A., D. E. Parker, E. B. Horton, C. K. Folland, L. V. Alexander, D. P. Rowell, E. C. Kent, and A. Kaplan, 2003: Global analyses of sea surface temperature, sea ice, and night marine air temperature since the late nineteenth century. J. Geophys. Res., 108, 4407, doi:10.1029/2002JD002670.

Reichler, T., and J. Kim, 2008: How well do coupled models simulate today's climate? Bull. Amer. Meteor. Soc., 89, 303-311, doi:10.1175/BAMS-89-3-303.

Sanderson, B. M., R. Knutti, and P. Caldwell, 2015a: A representative democracy to reduce interdependency in a multimodel ensemble. J. Climate, 28, 5171-5194, doi:10.1175/ JCLI-D-14-00362.1.

2015b: Addressing interdependency in a multimodel ensemble by interpolation of model properties. J. Climate, 28, 5150-5170, doi:10.1175/ JCLI-D-14-00361.1.
Schaller, N., I. Mahlstein, J. Cermak, and R. Knutti, 2011: Analyzing precipitation projections: A comparison of different approaches to climate model evaluation. J. Geophys. Res., 116, D10118, doi:10.1029/2010JD014963.

Schär, C., P. L. Vidale, D. Lüthi, C. Frei, C. Häberli, M. A. Liniger, and C. Appenzeller, 2004: The role of increasing temperature variability in European summer heatwaves. Nature, 427, 332 336, doi:10.1038/nature02300.

Schneider, T., T. Bischoff, and H. Płotka, 2015: Physics of changes in synoptic midlatitude temperature variability. J. Climate, $\mathbf{2 8}$, 2312-2331, doi:10.1175/JCLI-D-14-00632.1.

Screen, J. A., 2014: Arctic amplification decreases temperature variance in northern mid- to high-latitudes. Nat. Climate Change, 4, 577-582, doi:10.1038/nclimate2268.

, and I. Simmonds, 2010: The central role of diminishing sea ice in recent Arctic temperature amplification. Nature, 464, 13341337, doi:10.1038/nature09051.

- and - 2011: Erroneous Arctic temperature trends in the ERA-40 reanalysis: A closer look. J. Climate, 24, 2620-2627, doi:10.1175/2010JCLI4054.1.

$\longrightarrow$, and - 2013: Exploring links between Arctic amplification and mid-latitude weather. Geophys. Res. Lett., 40, 959-964, doi:10.1002/grl.50174.

, C. Deser, I. Simmonds, and R. Tomas, 2014: Atmospheric impacts of Arctic sea-ice loss, 1979-2009: Separating forced change from atmospheric internal variability. Climate Dyn., 43, 333-344, doi:10.1007/s00382-013-1830-9.

-,- - , and L. Sun, 2015: Reduced risk of North American cold extremes due to continued Arctic sea ice loss. Bull. Amer. Meteor. Soc., 96, 1489-1503, doi:10.1175/ BAMS-D-14-00185.1.

Seneviratne, S. I., D. Lüthi, M. Litschi, and C. Schär, 2006: Landatmosphere coupling and climate change in Europe. Nature, 443, 205-209, doi:10.1038/nature05095.

Serreze, M. C., and R. G. Barry, 2011: Processes and impacts of Arctic amplification: A research synthesis. Global Planet. Change, 77, 85-96, doi:10.1016/j.gloplacha.2011.03.004.

Sherwood, S. C., S. Bony, and J.-L. Dufresne, 2014: Spread in model climate sensitivity traced to atmospheric convective mixing. Nature, 505, 37-42, doi:10.1038/nature12829.

Son, S. W., and Coauthors, 2010: Impact of stratospheric ozone on Southern Hemisphere circulation change: A multimodel assessment. J. Geophys. Res., 115, D00M07, doi:10.1029/ 2010JD014271.

Stegehuis, A. I., A. J. Teuling, P. Ciais, R. Vautard, and M. Jung, 2013: Future European temperature change uncertainties reduced by using land heat flux observations. Geophys. Res. Lett., 40, 2242-2245, doi:10.1002/grl.50404.

Stocker, T. F., and Coauthors, 2013: Technical summary. Climate Change 2013: The Physical Science Basis, T. F. Stocker et al., Eds., Cambridge University Press, 33-115.

Stroeve, J. C., V. Kattsov, A. Barrett, M. Serreze, T. Pavlova, M. Holland, and W. N. Meier, 2012: Trends in Arctic sea ice extent from CMIP5, CMIP3 and observations. Geophys. Res. Lett., 39, L16502, doi:10.1029/2012GL052676.

Su, H., J. H. Jiang, C. Zhai, T. J. Shen, J. D. Neelin, G. L. Stephens, and Y. L. Yung, 2014: Weakening and strengthening structures in the Hadley circulation change under global warming and implications for cloud response and climate sensitivity. J. Geophys. Res. Atmos., 119, 5787-5805, doi:10.1002/ 2014JD021642.

Sun, L., C. Deser, and R. A. Tomas, 2015: Mechanisms of stratospheric and tropospheric circulation response to projected 
Arctic sea ice loss. J. Climate, 28, 7824-7845, doi:10.1175/ JCLI-D-15-0169.1.

Swart, N. C., J. C. Fyfe, E. Hawkins, J. E. Kay, and A. Jahn, 2015: Influence of internal variability on Arctic sea-ice trends. Nat. Clim. Chang., 5, 86-89, doi:10.1038/nclimate2483.

Tan, I., T. Storelvmo, and M. D. Zelinka, 2016: Observational constraints on mixed-phase clouds imply higher climate sensitivity. Science, 352, 224-227, doi:10.1126/science.aad5300.

Tang, Q., X. Zhang, X. Yang, and J. A. Francis, 2013: Cold winter extremes in northern continents linked to Arctic sea ice loss. Environ. Res. Lett., 8, 014036, doi:10.1088/1748-9326/8/1/014036.

Taylor, K. E., R. J. Stouffer, and G. A. Meehl, 2012: An overview of CMIP5 and the experiment design. Bull. Amer. Meteor. Soc., 93, 485-498, doi:10.1175/BAMS-D-11-00094.1.

Tebaldi, C., and R. Knutti, 2007: The use of the multi-model ensemble in probabilistic climate projections. Philos. Trans. Roy. Soc., 365A, 2053-2075, doi:10.1098/rsta.2007.2076.

Thorne, P. W., 2008: Arctic tropospheric warming amplification? Nature, 455, E1-E2, doi:10.1038/nature07256.

Tian, B., 2015: Spread of model climate sensitivity linked to double-intertropical convergence zone bias. Geophys. Res. Lett., 42, 4133-4141, doi:10.1002/2015GL064119.
Vihma, T., 2014: Effects of Arctic sea ice decline on weather and climate: A review. Surv. Geophys., 35, 1175-1214, doi:10.1007/ s10712-014-9284-0.

Weigel, A. P., R. Knutti, M. A. Liniger, and C. Appenzeller, 2010: Risks of model weighting in multimodel climate projections. J. Climate, 23, 4175-4191, doi:10.1175/2010JCLI3594.1.

Wenzel, S., V. Eyring, E. P. Gerber, and A. Y. Karpechko, 2016: Constraining future summer austral jet stream positions in the CMIP5 ensemble by process-oriented multiple diagnostic regression. J. Climate, 29, 673-687, doi:10.1175/ JCLI-D-15-0412.1.

Wettstein, J. J., and C. Deser, 2014: Internal variability in projections of twenty-first-century Arctic sea ice loss: Role of the large-scale atmospheric circulation. J. Climate, 27, 527-550, doi:10.1175/JCLI-D-12-00839.1.

Ylhäisi, J. S., and J. Räisänen, 2014: Twenty-first century changes in daily temperature variability in CMIP3 climate models. Int. J. Climatol., 34, 1414-1428, doi:10.1002/joc.3773.

Zhang, Y., D. J. Seidel, J.-C. Golaz, C. Deser, and R. A. Tomas, 2011: Climatological characteristics of Arctic and Antarctic surface-based inversions. J. Climate, 24, 5167-5186, doi:10.1175/ 2011JCLI4004.1. 